\title{
Immunosuppression-induced bronchial epithelial-mesenchymal transition: A potential contributor to obliterative bronchiolitis
}

\author{
Valerie M. Felton, Landon J. Inge, PhD, Brigham C. Willis, MD, Ross M. Bremner, MD, and \\ Michael A. Smith, MD
}

\begin{abstract}
Objective: Obliterative bronchiolitis is the predominant histopathologic finding in patients with chronic rejection after lung transplant. This fibroproliferative transformation within small airways of lung allograft is poorly understood; however, studies suggest epithelial-mesenchymal transition plays a role. Transplant immunosuppressive therapy has been shown to cause epithelial-mesenchymal transition in renal tubular epithelial cells, with subsequent fibrosis. This study explored whether immunosuppressive therapy contributes to epithelial-mesenchymal transition in airway epithelial cells.
\end{abstract}

Methods: Bronchial epithelial cell line RL-65 was treated 3 to 5 days with several immunosuppressive agents, including cyclosporine (INN ciclosporin), tacrolimus, azathioprine, mycophenolic acid, sirolimus, prednisone, and transforming growth factor $\beta 1$ as control. We then analyzed cells for presence of mesenchymal morphology and protein markers.

Results: Treatment with cyclosporine, azathioprine, mycophenolate, and sirolimus resulted in elongated and irregular cell shape, and all but azathioprine showed loss of cell-cell adhesions relative to vehicle-treated cells. Expressions of extracellular matrix proteins, fibronectin and collagen, along with mesenchymal marker, vimentin, were significantly upregulated. Immunofluorescence showed loss of E-cadherin at cell membranes and cytoskeletal rearrangements typical of epithelial-mesenchymal transition. These immunosuppressive agents also increased transforming growth factor produced by cells; however, tacrolimus- and prednisone-treated cells maintained epithelial morphology, baseline levels of matrix protein expression, and transforming growth factor production levels.

Conclusions: Overall, we found that certain immunosuppressive agents may contribute to partial epithelialmesenchymal transition in bronchial epithelial cells, specifically increasing production of excessive extracellular matrix proteins. This may provide novel insights into the pathogenesis of obliterative bronchiolitis after lung transplant. (J Thorac Cardiovasc Surg 2011;141:523-30)

Lung transplant is the preferred management strategy for selected patients with progressive end-stage lung disease. Improvements in donor and recipient selection, surgical techniques, and immunosuppression have led to substantial gains in short-term survival, with current 1-year survival approaching $85 \%$; however, long-term outcomes after lung transplant remain much lower than desired, with 5-year survival approximately 50\% according to Organ Procurement and Transplant Network data as of January 1, 2010 (http:// optn.transplant.hrsa.gov). The primary factor limiting longterm survival after transplant is chronic rejection, the histologic manifestation of which is obliterative bronchiolitis

\footnotetext{
From the Center for Thoracic Disease, Heart and Lung Institute, St Joseph's Hospital and Medical Center, Phoenix, Ariz.

Disclosures: Authors have nothing to disclose with regard to commercial support.

Read at the 36th Annual Meeting of The Western Thoracic Surgical Association, Ojai, Calif, June 23-26, 2010.

Received for publication June 22, 2010; revisions received Sept 24, 2010; accepted for publication Oct 3, 2010; available ahead of print Dec 16, 2010.

Address for reprints: Michael A. Smith, MD, 500 W Thomas Rd, Ste 500, Phoenix AZ 85013 (E-mail: Michael.Smith011@chw.edu).

$0022-5223 / \$ 36.00$

Copyright (c) 2011 by The American Association for Thoracic Surgery doi:10.1016/j.jtcvs.2010.10.006
}

(OB). ${ }^{1} \mathrm{OB}$ is characterized by remodeling and fibrotic obstruction of the smaller airways. ${ }^{2}$ This is essentially an irreversible process that leads to progressive airflow limitation and allograft dysfunction, resulting in substantial patient morbidity and mortality.

The pathogenesis of OB remains poorly understood; however, clinical observations and in vitro investigations have suggested that $\mathrm{OB}$ may represent a pathologic healing response from cellular and antibody-mediated alloimmune injury, as well as virally mediated injury to the airway epithelium. ${ }^{3,4}$ It is increasingly recognized that clinically silent injuries also occur that may lead to airway epithelial injury and subsequent chronic rejection. During this healing response, fibroblasts will contract, causing wound closure, and lay down extracellular matrix (ECM) for new epithelium to grow along. Improperly regulated ECM deposition is thought to result in excess nonfunctional fibrous tissue, such as that seen in idiopathic pulmonary fibrosis. The fibrous buildup within the walls of small airways in OB may result from a similar process.

The origin of the fibroblasts responsible for the airway wall fibrosis and luminal occlusion is unknown. Potential sources include in situ proliferation of resident fibroblasts 


$$
\begin{aligned}
& \text { Abbreviations and Acronyms } \\
& \begin{aligned}
\text { AQP5 } & =\text { aquaporin } 5 \\
\text { ECAD } & =\text { E-cadherin } \\
\text { ECM } & =\text { extracellular matrix } \\
\text { EMT } & =\text { epithelial-mesenchymal transition } \\
\text { OB } & =\text { obliterative bronchiolitis } \\
\text { TGF- } \beta 1 & =\text { transforming growth factor } \beta 1
\end{aligned}
\end{aligned}
$$

and recruitment of circulating mesenchymal stem cells., ${ }^{5,6}$ There has also been increasing interest in the ability of epithelial cells to undergo epithelial-mesenchymal transition (EMT) mediated by transforming growth factor $\beta 1$ (TGF- $\beta 1$ ). EMT has been demonstrated in many organ epithelial cell types and disease processes. In the lung, it has primarily been described in alveolar epithelial cells and is thought to be a primary contributor to the pathogenesis of pulmonary fibrosis. ${ }^{7}$ More recently, others have demonstrated that bronchial epithelial cells also have the capacity to undergo TGF- $\beta 1$-mediated EMT. ${ }^{8}$ EMT may therefore play a role in the development of OB by resulting in the transition of airway epithelium to fibroblastlike cells that deposit excess ECM, constricting the airway.

TGF- $\beta 1$ has been implicated as the main cytokine triggering EMT. Increased TGF- $\beta 1$ is associated with both clinical and experimental OB..$^{9,10}$ In addition, immunosuppressive agents such as cyclosporine (INN ciclosporin) induce renal tubular interstitial fibrosis. ${ }^{11}$ Furthermore, it has been shown that the fibrogenic nature of cyclosporine is secondary to proximal tubular renal epithelial cell EMT that is associated with upregulation of TGF- $\beta 1$ secretion. We therefore hypothesized that immunosuppressive drugs also contribute to the fibrosis of the airways by triggering EMT in bronchial airway epithelial cells.

In this study, we sought to characterize further the capacity of bronchial epithelial cells to undergo EMT and to determine whether common immunosuppressive drugs play a role in the induction of EMT in bronchial epithelial cells. We examined total cellular concentrations of epithelial and mesenchymal markers with immunoblot and localization changes of markers with immunofluorescence. We quantified the productions of the ECM proteins excreted from the cells in the presence of each drug. Finally, we assessed whether the cause of increased ECM protein production was an increase in TGF- $\beta 1$ production by the epithelial cells themselves.

\section{MATERIALS AND METHODS \\ Cell Culture}

RL-65 cells, a spontaneously immortalized rat bronchial epithelial cell line, ${ }^{12}$ were purchased from ATCC (Manassas, Va) and cultured in Dulbecco modified Eagle medium and F12-Hamm medium supplemented with 2.5-mmol/L glutamine, 5-mmol/L insulin, $10-\mathrm{mg}$ transferrin, $2.5-\mathrm{mL}$ bovine pituitary extract, nonessential amino acids, $100-\mathrm{U} / \mathrm{mL}$ penicillin, and $100-\mu \mathrm{g} / \mathrm{mL}$ streptomycin. Cells were treated with vehicle $(5 \mu \mathrm{L}$ dimethylsulfoxide), $2.5-\mathrm{ng} / \mathrm{mL}$ recombinant human TGF- $\beta 1$ (R\&D Systems, Inc, Minneapolis, Minn), or immunosuppressive drugs. Immunosuppressive drugs cyclosporine, tacrolimus, azathioprine, mycophenolic acid, and prednisone were purchased from Sigma (Sigma-Aldrich Co, St Louis, Mo) and sirolimus was purchased from Calbiochem (EMD Chemicals Inc, Gibbstown, NJ). Doses for each drug were as follows: cyclosporine $1 \mu \mathrm{mol} / \mathrm{L}$, tacrolimus $5 \mu \mathrm{mol} / \mathrm{L}$, azathioprine $500 \mathrm{nmol} / \mathrm{L}$, mycophenolic acid $500 \mathrm{nmol} / \mathrm{L}$, sirolimus $20 \mathrm{nmol} / \mathrm{L}$, and prednisone $5 \mu \mathrm{mol} / \mathrm{L}$. Drug doses were determined from published patient and pharmacokinetic data and adjusted for tolerance by the cell line. ${ }^{13,14}$ Because bioavailability of immunosuppressive compounds varies highly among patients, we used the highest dose within therapeutic range before a loss of cell viability was seen. Tacrolimus, for example, was assayed at a higher than normal dose because of a high tolerance for the drug by the cells. Cells were redosed every 24 hours and maintained at $37^{\circ} \mathrm{C}$ and $5 \%$ carbon dioxide for 3 to 5 days. Cell viability and metabolic activity were confirmed with a Resazurin fluorescence conversion assay (Promega Corporation, Madison, Wis). No significant loss of cell viability was seen at chosen doses.

\section{Immunoblotting}

After treatment, cell cultures were lysed with sodium dodecylsulfate buffer and sonicated. Protein concentrations were estimated with a detergent-compatible assay kit from Bio-Rad (Bio-Rad Laboratories, Hercules, Calif). Samples were run on a $10 \%$ acrylamide gel, transferred to nitrocellulose membrane, blocked, and incubated overnight at $4{ }^{\circ} \mathrm{C}$ with appropriate primary antibody. Primary antibodies included antifibronectin antibody (Sigma), anti-aquaporin 5 (AQP5) antibody (Santa Cruz Biotechnology, Inc, Santa Cruz, Calif), anti-E-cadherin (ECAD) antibody (BD Bioscience, BD, Franklin Lakes, NJ), antivimentin antibody (Sigma), and anti-B-actin antibody (Sigma). Membranes were washed and incubated with horseradish peroxidase-conjugated secondary antibodies (Cell Signaling Technology, Inc, Danvers, Mass) for 2 hours at room temperature. Membranes were developed and imaged on a Kodak Image Station (Eastman Kodak Company, Rochester, NY).

\section{Immunofluorescence}

Cells were grown on coverslips and treated as stated previously, then fixed for 30 minutes with $4 \%$ paraformaldehyde. Coverslips were repermeabilized with methanol or $0.2 \%$ Triton-X 100 (Dow Chemical Company, Midland, Mich), blocked, and incubated overnight at $4{ }^{\circ} \mathrm{C}$ with primary antibody. Alexaflour 488 (Life Technologies, Carlsbad, Calif) secondary antibody and conjugated phalloidin antibody incubation was carried out at room temperature for 2 hours. Coverslips were then mounted on slides with Vectashield (Vector Laboratories, Inc, Burlingame, Calif) with 4',6-diamidino-2-phenylindole and imaged. Brightfield images of cell cultures were taken at equivalent time points.

\section{Soluble Collagen Assay}

Media samples from cell cultures were harvested after 5 days of treatment and a full 24 hours after last medium change. Samples were incubated with binding dye, Sirius red (Sircol; Biocolor Ltd, Carrickfergus, UK) assay for soluble collagens. Dye-bound samples were pelleted, resuspended in buffer, then plated on a 96-well plate. Absorbance was measured at 535 $\mathrm{nm}$. Measurements were normalized to total protein concentration taken from the samples at the time of media harvest.

\section{TGF- $\beta 1$ Enzyme-Linked Immunosorbent Assay}

Medium samples from cell cultures were harvested after 2 full days of pretreatment with immunosuppressive drugs, then allowing for another full 24 hours of TGF- $\beta 1$ secretion with fresh media. Samples were treated to measure content of total excreted cytokine, including active and 
latent TGF- $\beta 1$. Samples were assayed on a TGF- $\beta 1$ enzyme-linked immunosorbent assay (R\&D Systems) plate and read at $450 \mathrm{~nm}$. Measurements were normalized to total cellular protein concentration of lysates taken at the time of medium harvest.

\section{Anti-TGF- $\beta 1$ Rescue}

To confirm that the effects of the immunosuppressive drugs on the cells were due to induced TGF- $\beta 1$ production, we pretreated the cells for 30 minutes with anti-TGF- $\beta 1(5 \mathrm{ng} / \mathrm{mL})$ before treating cells with TGF- $\beta 1$ or immunosuppressive drugs. This pretreatment was repeated for every medium change and redosing for 3 days. Cells were assessed morphologically, and lysates were analyzed by immunoblot for fibronectin production.

\section{Statistical Analysis}

Experiments were performed in triplicate. Quantitative analyses were expressed as mean $\pm \mathrm{SEM}$.

\section{RESULTS}

\section{Cell Morphology}

Vehicle-treated cells exhibited a typical epithelial morphology (Figure 1), including a consistent round shape and a tightly junctioned monolayer. Cells treated with TGF- $\beta 1$ begin to detach from each other, losing cell-cell adhesion, and to elongate and flatten out significantly. Cyclosporine-, mycophenolic acid-, and sirolimus-treated cells mimicked the morphology changes observed with TGF- $\beta 1$ treatment, including loss of cell adhesions and change in cell shape. Azathioprine-treated cells; however, showed irregularity in cell shape without the loss of cell-cell contact seen in TGF- $\beta 1$-treated cells. Cells treated with tacrolimus and prednisone exhibited no change in morphology and were nearly indistinguishable from untreated control cells.

\section{Expressions of Epithelial and Mesenchymal Markers}

Expressions of the epithelial and mesenchymal markers were assessed by immunoblot (Figure 2). The epithelial markers AQP5 and ECAD were highly expressed in vehicle-treated cells. In the presence of TGF- $\beta 1$, the cells lost their AQP5 expression, and with each immunosuppressive drug treatment, expression of AQP5 nearly disappeared. Overall expression of ECAD, a tight junction protein, was not reduced in the presence of TGF- $\beta 1$ or immunosuppressive drugs.

The mesenchymal markers fibronectin and vimentin are normally expressed at low or undetectable levels. The ECM protein fibronectin showed a marked increase with TGF- $\beta 1$ treatment, as well as with cyclosporine, mycophenolic acid, and sirolimus treatments. A slight increase was also noted with azathioprine treatment. Vimentin expression was increased in response to both TGF- $\beta 1$ and immunosuppressive drug treatments. Notably, however, this was a much less pronounced increase than we saw in preliminary experiments with alveolar type II cells. Tacrolimus- and prednisonetreated cells were comparable to vehicle-treated cells in levels of mesenchymal marker expression.

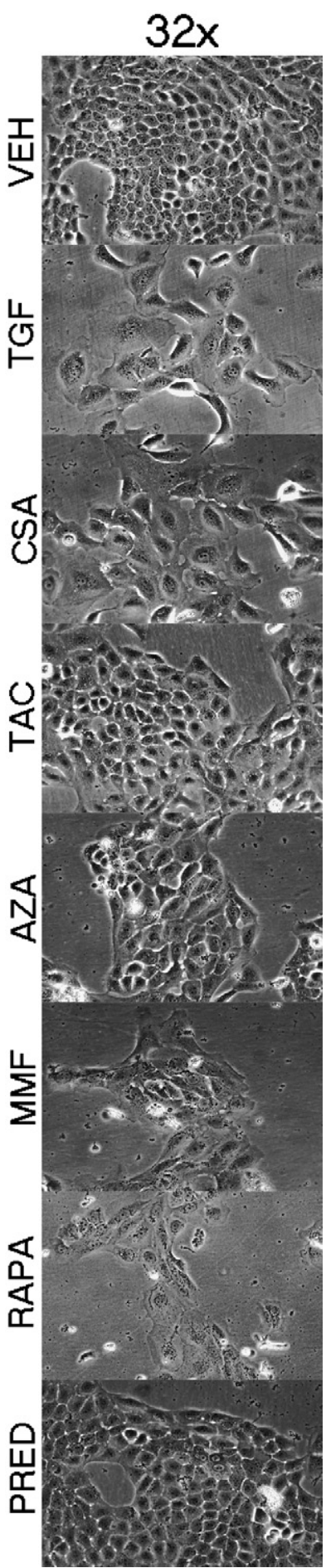

FIGURE 1. Morphology of immunosuppressive drug treated bronchial epithelium. RL-65 cells normally exhibit consistent round shape and tightly junctioned cobblestone monolayer. In presence of transforming growth factor $\beta 1(T G F)$, however, cells began to flatten, elongate, and lose cell-cell adhesions, adopting more fibroblastlike morphology. Similar changes were seen in response to cyclosporine (CSA), mycophenolic acid (MMF), and sirolimus (RAPA). Azathioprine $(A Z A)$ elicited elongated and inconsistent cell shape with noticeably less loss of cell-cell adhesions. Cells treated with tacrolimus (TAC) and prednisone (PRED) were indistinguishable from those treated with vehicle (VEH). 


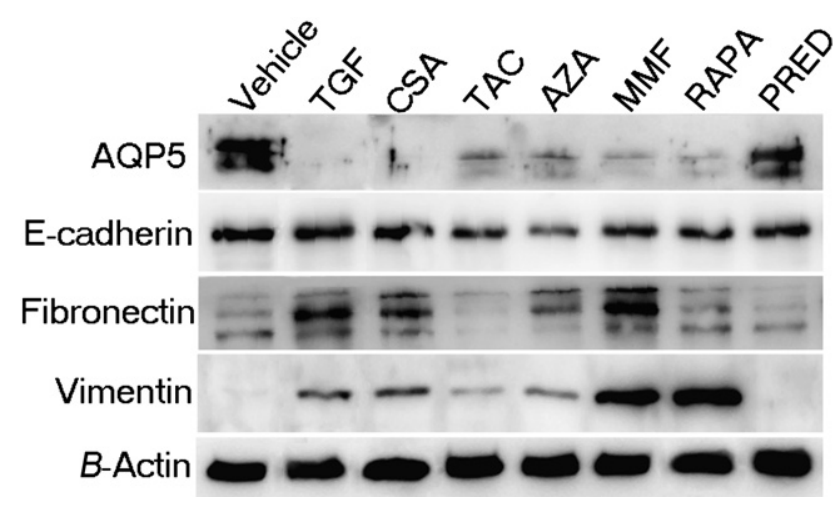

FIGURE 2. Immunoblot analysis of epithelial and mesenchymal markers. Cell lysates were analyzed for epithelial markers aquaporin 5 (AQP5) and E-cadherin. Aquaporin 5 expression ceased in presence of transforming growth factor $\beta 1(T G F)$ and in cells treated with cyclosporine (CSA). Cells treated with tacrolimus $(T A C)$, azathioprine $(A Z A)$, mycophenolic acid $(M M F)$, and sirolimus (RAPA) all demonstrated significant loss of aquaporin 5 expression. Expression of E-cadherin remained consistent with control cells for transforming growth factor $\beta 1$ and all drug treatments. Expression of mesenchymal marker and ECM protein fibronectin was greatly increased in response to transforming growth factor $\beta 1$. Cyclosporine and mycophenolic acid elicited increased expression levels of fibronectin, similar to that of transforming growth factor $\beta 1$. Azathioprine-treated cells showed slight increase in both fibronectin and vimentin. Prednisone-treated cells exhibited similar expression profile to that of vehicle-treated cells.

\section{Localization Changes of EMT Markers}

Immunofluorescence was used to assess changes in localization of epithelial and mesenchymal markers (Figure 3). Phalloidin staining was used to assess actin cytoskeletal changes. Vehicle-treated cells maintained a honeycomb cortical actin ring at the membrane of each cell, whereas TGF- $\beta 1$-treated cells lost this ring and began displaying stress fibers throughout the cell. Cyclosporine-, mycophenolic acid-, and sirolimus-treated cells displayed this altered actin organization with loss of actin ring and mild formation of stress fibers, resembling TGF- $\beta 1$-treated cells, whereas cells treated with tacrolimus, azathioprine, and prednisone generally maintained cytoskeletal structure and integrity of the actin ring.

ECAD localization in TGF- $\beta 1$-treated cells was distinctly different from that in vehicle-treated cells, even though no decrease in overall expression level was seen by immunoblot, as stated previously. TGF- $\beta 1$-treated cells showed a distinct loss of ECAD at the cell membrane. Cyclosporine-, mycophenolic acid-, and sirolimus-treated cells also lost ECAD at the cell membrane. Tacrolimus-, azathioprine-, and prednisone-treated cells maintained cell-cell junctions and localization of ECAD at the cell membrane.

TGF- $\beta 1$-treated cells made large deposits of fibronectin relative to vehicle-treated cells. Cyclosporine, mycophenolic acid-, and sirolimus-treated cells also exhibited fibronectin deposition similar to that of TGF- $\beta 1$-treated cells, whereas tacrolimus-, azathioprine-, and prednisonetreated cells did not exhibit a large increase in fibronectin deposition. Azathioprine-treated cells, however, showed significant nuclear blebbing (image not shown), typically associated with preapoptotic cells, relative to mycophenolic acid treatment.

\section{Collagen Production}

Medium from cell cultures was harvested and analyzed for soluble collagen content excreted from cells (Figure 4). Vehicle-treated cells exhibited virtually no collagen production (denoted 1 -fold). TGF- $\beta 1$-treated cells had nearly a 5 -fold increase in collagen production relative

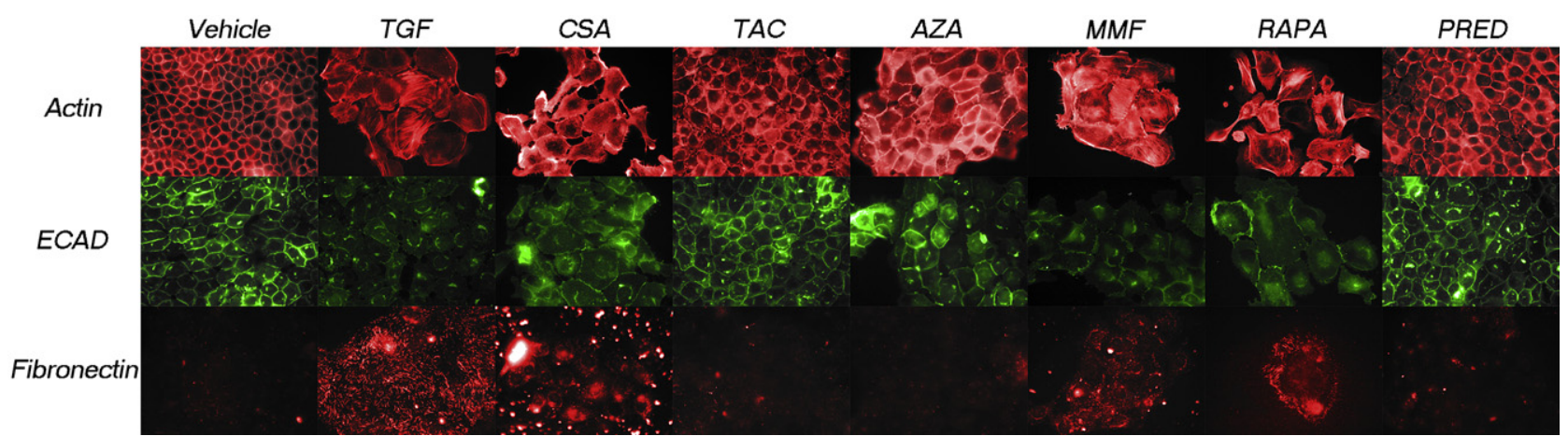

FIGURE 3. Immunofluorescence localization of epithelial and mesenchymal markers. Actin cytoskeleton of vehicle-treated RL-65 cells showed intact cortical actin ring throughout cell monolayer. Treatment with transforming growth factor $\beta 1(T G F)$ resulted in loss of actin ring and formation of visible stress fibers. Cyclosporine (CSA), mycophenolic acid $(M M F)$, and sirolimus (RAPA) treatments mimicked cytoskeletal rearrangements of transforming growth factor $\beta 1$. Azathioprine (AZA)-treated cells maintained their cortical actin ring; however, overall shape of the ring seemed to be elongated and irregular compared with VEH-treated cells. Transforming growth factor $\beta 1$, cyclosporine, mycophenolic acid, and sirolimus also resulted in loss of E-cadherin $(E C A D)$ localization at cell membrane relative to vehicle-treated cells, whereas cells exposed to tacrolimus (TAC) and prednisone (PRED) maintained cortical actin ring and membrane-associated E-cadherin expression. Transforming growth factor $\beta 1$ treatment greatly increased fibronectin deposition, as did cyclosporine, mycophenolic acid, and sirolimus treatments. AZA-treated cells expressed increased fibronectin compared with VEH while also maintaining ECAD expression. Tacrolimus- and prednisone-dosed cells maintained baseline levels of fibronectin expression. 


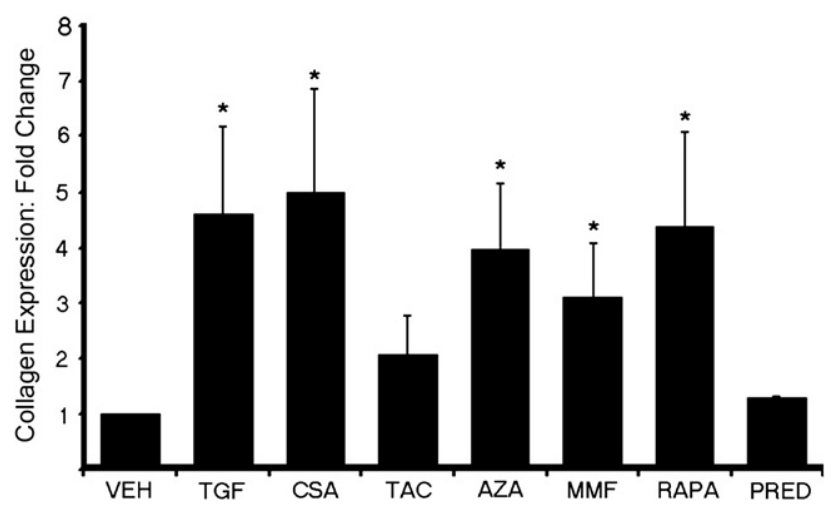

FIGURE 4. Collagen production. Medium harvested from cell cultures was analyzed for presence of soluble collagen and normalized to total protein from same cultures. Cells treated with vehicle ( $V E H)$ exhibited virtually no collagen secretion, which we scaled to 1 . Cells treated with transforming growth factor $\beta 1$ (TGF) had nearly 5 -fold increase in collagen production relative to vehicle-treated cells. Cells treated with cyclosporine (CSA) and sirolimus (RAPA) showed largest increases in collagen production, both at similar levels to transforming growth factor $\beta 1$-treated cells. Cells treated with mycophenolic acid $(M M F)$ and azathioprine $(A Z A)$ exhibited 3- and 4-fold increases in collagen production, respectively. Cells treated with tacrolimus (TAC) and prednisone (PRED) were comparable to vehicle-treated cells. Asterisk indicates significant difference from vehicle, $P<.05$.

to vehicle-treated cells. Cyclosporine-treated cells also had a 5-fold increase in collagen production. The collagen production increases in azathioprine-, mycophenolic acid-, and sirolimus-treated cells ranged from 3- to 4fold. Tacrolimus- and prednisone-treated cells showed no significant increase in soluble collagen production relative to vehicle-treated cells.

\section{TGF- $\beta 1$ Production}

With TGF- $\beta 1$ stimulation as a positive control, enzymelinked immunosorbent assay-detected TGF- $\beta 1$ was nearly 1.5-fold that of vehicle-treated cells (Figure 5, A). Prolonged exposure with cyclosporine resulted in the greatest induction of TGF- $\beta 1$ expression at just under a 1 -fold increase. Azathioprine- and mycophenolic acid-treated cells both exhibited a 0.5 -fold increase in TGF- $\beta 1$ production. Sirolimus showed nearly a 1 -fold increase in TGF- $\beta 1$ excretion similar to that of cyclosporine. Notably, tacrolimusand prednisone-treated cells had no significant upregulation of TGF- $\beta 1$ and were comparable to vehicle-treated cells.

\section{Anti-TGF- $\beta 1$ Rescue}

Previously we demonstrated fibronectin expression with exposure to TGF- $\beta 1$ and certain immunosuppressive drugs (Figure 2). In addition, coincubation with anti-TGF- $\beta 1$ successfully maintained expression of fibronectin at baseline levels in the presence of immunosuppressive drugs (Figure 5, B). Fibronectin was chosen because it is a main component of ECM, and we therefore considered it to be the most clinically relevant marker. By immunoblot, we compared levels of fibronectin after treatment with each immunosuppressant and anti-TGF- $\beta 1$ with TGF- $\beta 1$ alone as a positive control and with TGF- $\beta 1$ in the presence of anti-TGF- $\beta 1$ as a negative control. Fibronectin expression was preserved at baseline levels in the presence of all immunosuppressive drugs when cells were cotreated with anti-TGF- $\beta 1$.

\section{DISCUSSION}

In this study we showed the capacity of bronchial epithelial cells to undergo a partial EMT. We used the rat bronchial epithelial cell line RL-65 to show that stimulation with TGF- $\beta 1$ and also treatment with certain immunosuppressive agents increased expressions of the ECM proteins fibronectin and collagen. We confirmed the loss of epithelial marker AQP5 in the presence of each drug without, however, any noticeable loss in overall ECAD expression. We were nonetheless able to show a marked loss of ECAD localized to the cell membrane. Furthermore, we found that immunosuppressive agent-induced EMT was associated with upregulation of TGF- $\beta 1$ expression and that the presence of antiTGF- $\beta 1$ before administration of an immunosuppressive drug prevented this upregulation of fibronectin expression.

Despite great improvements in patient selection, surgical techniques, and postoperative care, the airway fibrosis with luminal narrowing of OB remains the most important limiting factor in long-term survival after lung transplant. The pathology of $\mathrm{OB}$ is poorly understood, but the current perspective is that $\mathrm{OB}$ is the result of chronic injuries from the host immune response, viral infections, and environmental contaminants. $^{3,4}$ In most instances, the airway epithelium is the target of these insults. ${ }^{15}$ We propose that chronic insults induce an improperly regulated wound healing response associated with increased TGF- $\beta 1$ expression. TGF- $\beta 1$, the main cytokine responsible for triggering EMT, could induce transition of airway epithelium to fibroblastlike cells, depositing ECM proteins and causing fibrous buildup within the airway walls.

Clinical evidence for EMT has been provided previously by Ward and colleagues, ${ }^{16}$ who showed EMT markers in allografts of stable lung transplant recipients. In addition, Borthwick and colleagues ${ }^{8}$ previously showed the capacity for EMT in human airway epithelial cells and a greater prevalence of EMT markers in patients with OB relative to stable recipients and control lung samples. Our data support these findings by demonstrating that another bronchial epithelial cell line has the capacity to downregulate epithelial markers in association with increased collagen, fibronectin, and vimentin in response to TGF- $\beta 1$ stimulation.

TGF- $\beta 1$ is a known mediator for the induction of fibrosis in many organs, including the lung. ${ }^{17}$ It is becoming increasingly recognized that much of this TGF- $\beta 1$-generated 


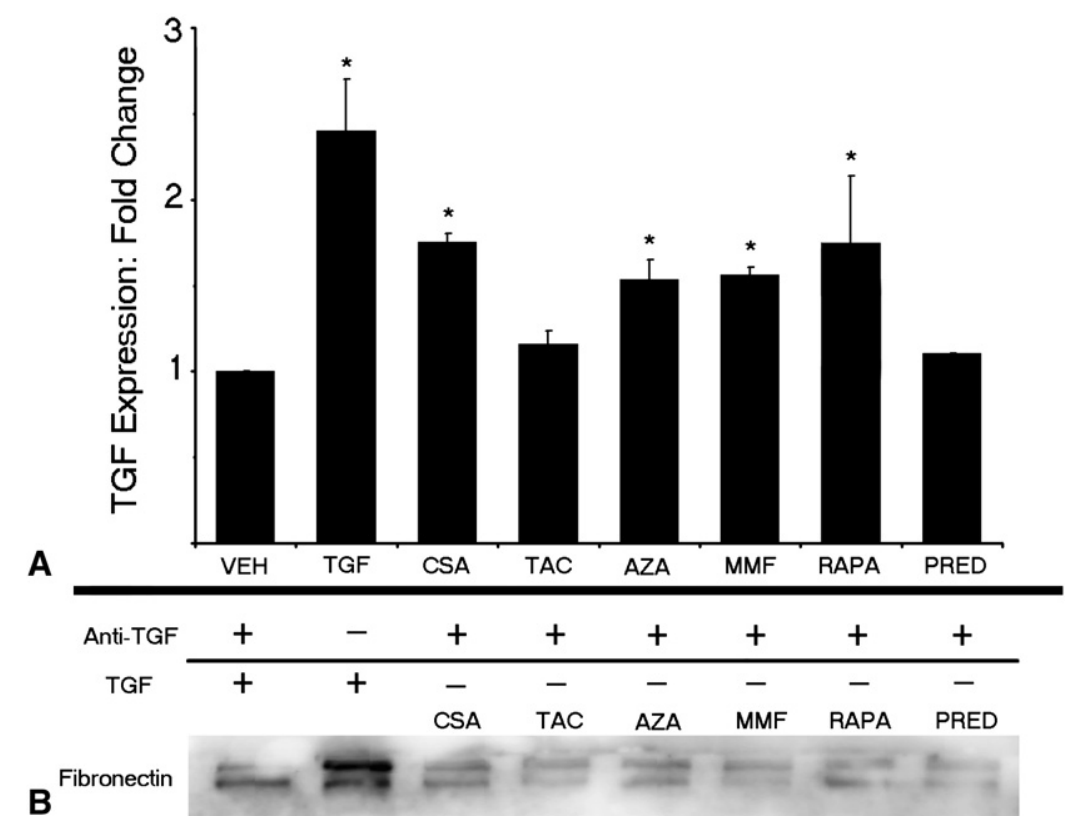

FIGURE 5. Transforming growth factor $\beta 1(T G F)$ production by bronchial epithelial cells and anti-transforming growth factor $\beta 1$ rescue. A, Presence of transforming growth factor $\beta 1$ in culture medium samples was assayed by enzyme-linked immunosorbent assay. Transforming growth factor $\beta 1$-positive control showed 1.5 -fold increase in present transforming growth factor $\beta 1$. Treatments with cyclosporine (CSA) and sirolimus (RAPA) elicited approximately 1.0-fold increases in transforming growth factor $\beta 1$ production relative to cells treated with vehicle $(V E H)$, whereas azathioprine $(A Z A)$ and mycophenolic acid $(M M F)$ treatments resulted in approximately 0.5 -fold increase. Cells treated with tacrolimus $(T A C)$ and prednisone $(P R E D)$ were comparable to vehicle-treated cells. B, To demonstrate immunosuppressive-induced transforming growth factor $\beta 1$ production as potential mechanism for immunosuppressive agent-induced epithelial-mesenchymal transition, we coincubated each immunosuppressive treatment with anti-transforming growth factor $\beta 1$. As negative control, cells were treated with $2.5-\mathrm{ng} / \mathrm{mL}$ transforming growth factor $\beta 1$ and $5-\mathrm{ng} / \mathrm{mL}$ anti-transforming growth factor $\beta 1$. Transforming growth factor $\beta 1$ alone served as positive control. Each immunosuppressive drug treatment coincubated with anti-transforming growth factor $\beta 1$ resulted in maintenance of baseline fibronectin levels. Asterisk indicates significant difference from vehicle, $P<.05$.

fibrogenesis, repair, scar formation, and deposition of ECM in tissues is mediated through EMT. In the lung, EMT has been most thoroughly examined in alveolar type II cells, including how their ability to transition into myofibroblasts contributes to idiopathic pulmonary fibrosis. ${ }^{18}$ It is known that TGF- $\beta 1$ is upregulated in the lungs of patients with idiopathic pulmonary fibrosis. ${ }^{19}$ Similarly, investigators have shown a prominent role for TGF- $\beta 1$ in the pathogenesis of both clinical and experimental OB. El-Gamel and associates $^{9}$ found that increased TGF- $\beta 1$ production both correlated with and preceded histologic presentation of $\mathrm{OB}$ in transplant recipients. Experimentally, Ramirez and coworkers $^{20}$ prevented the manifestation of OB in tracheal transplant models by blocking TGF- $\beta 1-$ SMAD3 signaling, showing that this cytokine signaling pathway is essential in the development of OB.

Improvements in immunosuppression strategies have been central to the long-term success of all solid organ transplants. Historically, it was the discovery of the immunosuppressive effects of cyclosporine that revolutionized the field of solid organ transplantation. The primary limitation to the long term use of cyclosporine has been irreversible renal toxicity, which is characterized histologically by renal interstitial fibrosis. ${ }^{21}$ There is evidence that suggests that cyclosporine- induced renal tubulointerstitial fibrosis is mediated by proximal tubular epithelial cell EMT. ${ }^{11}$ Furthermore, others have reported that the profibrotic effects of cyclosporine on proximal tubular epithelial cells is associated with upregulation of TGF- $\beta 1 .^{22}$ These observations led us to consider whether immunosuppressive agents could contribute to the fibrotic airway remodeling seen in $\mathrm{OB}$, and whether disparities in clinically observed treatment outcomes were related to the immunosuppressive agent-induced fibrosis.

Our data similarly demonstrate that cyclosporine can trigger an EMT response in bronchial epithelial cells. Cyclosporine upregulated expressions of fibronectin and vimentin. In addition, collagen synthesis was increased in the presence of cyclosporine. Meanwhile, expression of the epithelial marker AQP5 was downregulated in the presence of cyclosporine. There was no difference in the overall expression of the epithelial marker ECAD; however, immunofluorescence demonstrated a distinct change in the cellular localization of ECAD, as well as actin cytoskeletal rearrangement. The loss of ECAD at the membrane suggests transition toward a motile phenotype, as seen in classic EMT; because the cells do not downregulate overall ECAD expression, however, the cells may harbor a limited capacity to undergo complete EMT. It is interesting to note 
that, unlike cyclosporine, tacrolimus did not trigger an EMT response. This finding correlates with clinical evidence that patients treated with tacrolimus have a significantly lower incidence of OB than those treated with cyclosporine. ${ }^{23}$ Similarly, others have shown that in tissue culture cyclosporine but not tacrolimus induces upregulation of secretion of TGF- $\beta 1$ from human small airway epithelial cells. ${ }^{24}$

The agents azathioprine, mycophenolic acid, and sirolimus demonstrated similar responses to cyclosporine. From a clinical standpoint, the choice of purine synthesis inhibitors also seems to be shifting away from azathioprine and toward mycophenolic acid. With no differences in the management of the stages of chronic rejection, mycophenolic acid treatment of patients trended toward a small improvement in graft loss relative to azathioprine. ${ }^{25}$ In our study, we noticed similar effects of these drugs. Both advanced EMT in bronchial epithelium; however, mycophenolic acid showed significantly less nuclear blebbing, often a precursor to apoptosis caused by DNA damage, than did azathioprine. Although not mechanistically related to EMT, this decreased nuclear damage could be associated with the improved outcomes seen with mycophenolic acid relative to azathioprine. Furthermore, sirolimus has become an attractive drug option because of its lack of nephrotoxicity. Severe pulmonary toxicity has been reported, ${ }^{26}$ however, which may correlate to the severe effect observed on the lung epithelium morphology, EMT marker production, and TGF- $\beta 1$ and collagen production.

The exact mechanism of development of $\mathrm{OB}$ remains uncertain, but the potential role of EMT may lead to therapeutic targets-specifically, TGF- $\beta 1$ 's downstream actors. The lung is a highly susceptible organ, and general injuries to the epithelium such as from physical trauma, infection, or pollutants can result in triggered wound healing response and increased TGF- $\beta 1 .{ }^{3,27}$ As our data demonstrate, certain immunosuppressive drugs also increase TGF- $\beta 1$ production in bronchial epithelial cells. At this point we can only speculate on the mechanism of immunosuppressive agentinduced TGF- $\beta 1$ production, but we suspect that it is part of a general injury response to the toxic effects of the drugs. In addition, we found that the EMT triggering effects of immunosuppressive drugs were diminished in the presence of anti-TGF- $\beta 1$. It should be noted that chronic injuries potentially triggering EMT are not limited to immunosuppressive drug toxicity; however, management of this toxicity could prevent unnecessary exacerbation of $\mathrm{OB}$.

Limitations of this study include the use of an immortalized nonhuman cell line. Further studies should examine the capacity of primary human cells to undergo EMT in response to immunosuppressive agents. In addition, although animal models for OB lack rigor, the effects of certain immunosuppressive agents should be tested in an appropriate in vivo model. Furthermore, our data revealed an interesting discrepancy between EMT studies in bronchial epithe- lium and alveolar epithelium. Whereas studies on alveolar cells resulted in classic EMT, including significant upregulation of $\alpha$-smooth muscle actin, ${ }^{28}$ we did not detect any increase in $\alpha$-smooth muscle actin in our study (data not shown). Furthermore, the relative increase in vimentin was small relative to increases seen in studies done with alveolar epithelial cells. This may suggest that bronchial epithelium, or any nonprogenitor epithelial cell in the same organ, may have a limited capacity relative to type II alveolar cells to undergo what we define as EMT. Whereas EMT is typically thought to result in the emergence of myofibroblasts, we could be seeing a partial EMT phenotype capable of ECM protein production but limited in its motile and contractile facilities, perhaps explaining the distinct localization of fibrosis seen in OB as opposed to the distributed fibrotic foci seen in idiopathic pulmonary fibrosis. Unfortunately, this limitation was outside of the scope of this investigation, but it should be studied more closely in the future. We believe that this partial EMT response is directly relevant to the distinct fibrotic presentation of OB.

In conclusion, our study provides further evidence for the capacity of bronchial epithelium to undergo TGF- $\beta 1$-mediated EMT. Furthermore, we have demonstrated that cyclosporine and other immunosuppressive agents can trigger an EMT response that appears to be mediated at least in part by TGF- $\beta 1$. This study found that TGF- $\beta 1$ and the commonly used immunosuppressive drugs cyclosporine, mycophenolic acid, and sirolimus caused upregulations of the mesenchymal markers fibronectin and vimentin and also increased collagen production. Downregulation of the epithelial marker AQP5 was seen with these drugs, along with altered intracellular ECAD localization. These findings may have direct implications regarding the mechanism of airway remodeling and fibrosis seen in OB after lung transplant, as well as regarding selection of immunosuppressive agents. Understanding the mechanisms of immunosuppressive agent-induced bronchial epithelial EMT may lead to novel protective and therapeutic strategies in the management of $\mathrm{OB}$ after lung transplant.

We would like to thank the St. Joseph's Foundation (Phoenix, Ariz) for their generous support of this study and their support of the Heart and Lung Research Initiative.

\section{References}

\footnotetext{
1. Berry GJ, Brunt EM, Chamberlain D, Hruban RH, Sibley RK, Stewart S, et al. A working formulation for the standardization of nomenclature in the diagnosis of heart and lung rejection: Lung Rejection Study Group. The International Society for Heart Transplantation. J Heart Transplant. 1990;9:593-601.

2. Boehler A, Kesten S, Weder W, Speich R. Bronchiolitis obliterans after lung transplantation: a review. Chest. 1998;114:1411-26.

3. Halloran PF, Homik J, Goes N, Lui SL, Urmson J, Ramassar V, et al. The "injury response": a concept linking nonspecific injury, acute rejection, and long-term transplant outcomes. Transplant Proc. 1997;29:79-81.

4. Tullius SG, Tilney NL. Both alloantigen-dependent and -independent factors influence chronic allograft rejection. Transplantation. 1995;59:313-8.
} 
5. Epperly MW, Guo H, Gretton JE, Greenberger JS. Bone marrow origin of myofibroblasts in irradiation pulmonary fibrosis. Am J Respir Cell Mol Biol. 2003;29: 213-24.

6. Schurch W, Seemayer TA, Gabbiani G. The myofibroblast: a quarter century after its discovery. Am J Surg Pathol. 1998;22:141-7.

7. Willis BC, Borok Z. TGF- $\beta$-induced EMT: mechanisms and implications for fibrotic lung disease. Am J Physiol Lung Cell Mol Physiol. 2007;293: L525-34.

8. Borthwick LA, Parker SM, Brougham KA, Johnson GE, Gorowiec MR, Ward C, et al. Epithelial to mesenchymal transition (EMT) and airway remodelling after human lung transplantation. Thorax. 2009;64:770-7.

9. El-Gamel A, Sim E, Hasleton P, Hutchinson J, Yonan N, Egan J, et al. Transforming growth factor $\beta$ (TGF- $\beta$ ) and obliterative bronchiolitis following pulmonary transplantation. J Heart Lung Transplant. 1999;18:828-37.

10. Hodge S, Holmes M, Banerjee B, Musk M, Kicic A, Waterer G, et al. Posttransplant bronchiolitis obliterans syndrome is associated with bronchial epithelial to mesenchymal transition. Am J Transplant. 2009;9:727-33.

11. Slattery C, Campbell E, McMorrow T, Ryan MP. Cyclosporine A-induced renal fibrosis: a role for epithelial-mesenchymal transition. Am J Pathol. 2005;167: 395-407.

12. Roberts PE, Phillips DM, Mather JP. A novel epithelial cell from neonatal rat lung: isolation and differentiated phenotype. Am J Physiol. 1990;259(6 Pt 1): L415-25.

13. Monchaud C, Marquet P. Pharmacokinetic optimization of immunosuppressive therapy in thoracic transplantation: part II. Clin Pharmacokinet. 2009;48:489-516.

14. Masuda S, Inui K. An up-date review on individualized dosage adjustment of calcineurin inhibitors in organ transplant patients. Pharmacol Ther. 2006;112: 184-98.

15. Fernández FG, Jaramillo A, Chen C, Liu DZ, Tung T, Patterson GA, et al. Airway epithelium is the primary target of allograft rejection in murine obliterative airway disease. Am J Transplant. 2004;4:319-25.

16. Ward C, Forrest IA, Murphy DM, Johnson GE, Robertson H, Cawston TE, et al Phenotype of airway epithelial cells suggests epithelial to mesenchymal cell transition in clinically stable lung transplant recipients. Thorax. 2005;60: 865-71.
17. Sime PJ, O'Reilly KM. Fibrosis of the lung and other tissues: new concepts in pathogenesis and treatment. Clin Immunol. 2001;99:308-19.

18. Willis BC, duBois RM, Borok Z. Epithelial origin of myofibroblasts during fibrosis in the lung. Proc Am Thorac Soc. 2006;3:377-82.

19. Bergeron A, Soler P, Kambouchner M, Loiseau P, Milleron B, Valeyre D, et al. Cytokine profiles in idiopathic pulmonary fibrosis suggest an important role for TGF- $\beta$ and IL-10. Eur Respir J. 2003;22:69-76.

20. Ramirez AM, Shen Z, Ritzenthaler JD, Roman J. Myofibroblast transdifferentiation in obliterative bronchiolitis: TGF- $\beta$ signaling through smad3-dependent and -independent pathways. Am J Transplant. 2006;6:2080-8.

21. Myers BD, Ross J, Newton L, Luetscher J, Perlroth M. Cyclosporine-associated chronic nephropathy. $N$ Engl J Med. 1984;311:699-705.

22. Johnson DW, Saunders HJ, Johnson FJ, Huq SO, Field MJ, Pollock CA. Fibrogenic effects of cyclosporin $\mathrm{A}$ on the tubulointerstitium: role of cytokines and growth factors. Exp Nephrol. 1999;7:470-8.

23. Keenan RJ, Konishi H, Kawai A, Paradis IL, Nunley DR, Iacono AT, et al. Clinical trial of tacrolimus versus cyclosporine in lung transplantation. Ann Thorac Surg. 1995;60:580-5.

24. Zhang JG, Walmsley MW, Moy JV, Cunningham AC, Talbot D, Dark JH, et al. Differential effects of cyclosporin $\mathrm{A}$ and tacrolimus on the production of TGF- $\beta$ : implications for the development of obliterative bronchiolitis after lung transplantation. Transpl Int. 1998;11(Suppl. 1):S325-7.

25. Speich R, Schneider S, Hofer M, Irani S, Vogt P, Weder W, et al. Mycophenolate mofetil reduces alveolar inflammation, acute rejection and graft loss due to bronchiolitis obliterans syndrome after lung transplantation. Pulm Pharmacol Ther. 2010;23(5):445-9.

26. Gupte GL, Mahadevan S, Clarke JR, Alton H, Beath SV. Sirolimus-related pulmonary toxicity mimicking 'asthma like' symptoms. World J Gastroenterol. 2007; 13:5151-3.

27. Crosby LM, Waters CM. Epithelial repair mechanisms in the lung. Am J Physiol Lung Cell Mol Physiol. 2010;298:L715-31.

28. Willis BC, Liebler JM, Luby-Phelps K, Nicholson AG, Crandall ED, du Bois RM, et al. Induction of epithelial-mesenchymal transition in alveolar epithelial cells by transforming growth factor-beta1: potential role in idiopathic pulmonary fibrosis. Am J Pathol. 2005;166:1321-32. 